Molecular

Syndromology
Editorial - Late Breaking Chromosomes

Mol Syndromol 2020;11:239-242

DOI: $10.1159 / 000512565$
Received: October 26, 2020

Accepted: October 27, 2020

Published online: December 7, 2020

\title{
Chromothripsis and Duplications as Underappreciated Genomic Gremlins
}

In families with a sporadic patient, medical geneticists may search for de novo single nucleotide variants or de novo genome rearrangements. The latter are commonly distinguished as either simple, involving 1 or 2 chromosomal breaks, or complex, involving more than 2 breaks [Madan, 2013; Poot and Haaf, 2015]. Examples of simple genome rearrangements include reciprocal translocations and single deletions. Since reciprocal translocations and single deletions often exert pathogenic effects, and single duplications are generally considered to be benign, the latter have received less attention [Hannes et al., 2009]. This is not at all justified since duplications may occur in several constellations, with various mechanism(s) of origin and consequently distinct phenotypic impact.

Duplications may either occur in cis as direct or inverted tandem duplications, or as an insertion-duplication at a distinct locus or chromosome [Newman et al., 2015]. If a direct tandem duplication occurs adjacent to the original position, 2 functional copies of the gene will emerge. This is the case for most single duplications [Newman et al., 2015]. If the duplication locates inside the original gene in direct orientation, a gene fusion will take place. It is not a priori clear whether this fusion gene will be functional or not. If the duplication locates inside the original gene in the inverted orientation, the gene will be disrupted such that a gene fusion may or may not occur.
In all of the latter cases haploinsufficiency for the affected gene will ensue.

Regardless of their mechanism of origin, duplications in cis always involve at least 3 breaks. Hence, they should be considered complex rearrangements. It is difficult to envisage duplications as a result of chromosome shattering followed by random re-ligation of the fragments, i.e., chromothripsis [Liu et al., 2011]. More likely is that during DNA replication the replication fork stalls after it encountered an obstacle such as a Holliday junction. It then tries to bypass this replication block by switching to another partially replicated DNA strand. This step may be repeated several times, until a DNA break allows to unwind the DNA and thus to resolve the Holliday junction or bypass the blockage. Such a break will prompt subsequent re-replication of a piece of DNA using small stretches of homology. Such a process, denoted Fork Stalling and Template Switching/Microhomology-Mediated Break-Induced Replication (FoSTeS/MMBIR), may account for the highly irregular and unpredictable patterns of duplications, triplications, quadruplications, and inversions observed at the PLP1 and the MECP2 loci [Beck et al., 2015]. In an initial series, in all cases a single chromosome arm was affected and the process seemed to move from the centromere toward the telomere. This sets it apart from the randomness of a process such as chro- 
mothripsis [Liu et al., 2011; Kloosterman et al., 2012]. Subsequent studies have shown that this process may occur at multiple loci and may affect any chromosome [Carvalho and Lupski, 2016; Gu et al., 2016; Zhang et al., 2017]. Independently, a series of cases of multiple duplications on a single chromosome interspersed by diploid segments have been analyzed [Nazaryan-Petersen et al., 2018]. Their breakpoint junctions frequently contain microhomologies, which is consistent with serial template switching during DNA replication. Thus, this kind of complex genome rearrangements, probably involving FoSTeS/MMBIR, represents a separate entity, likely a form of chromoanasynthesis [Liu et al., 2011; NazaryanPetersen et al., 2018; Poot, 2018].

Duplications resulting from an insertion of a chromosomal segment into another chromosome may have been elicited by completely different mechanisms. Such insertional translocations (ITs), detected by copy number profiling, occur in $2.1-2.5 \%$ of patients with complex clinical phenotypes [Nowakowska et al., 2012; Newman et al., 2015]. This does not necessarily prove that ITs are by themselves pathogenic. In several families, these ITs were transmitted from a healthy parent to an affected child [de Pagter et al., 2015; Bertelsen et al., 2016; Kurtas et al., 2019]. This is not surprising since ITs may either be incorporated in an intergenic region, or disrupt an intron or an exon of a gene [de Pagter et al., 2015; Newman et al., 2015]. Insertion into an intergenic region may only be pathogenic if this disrupts a topologically associated domain [Lupiáñez et al., 2016]. If introduced inside a gene, regardless of its orientation, the inserted segment may disrupt the target gene, which most likely provokes haploinsufficiency [Newman et al., 2015]. Only if the gene is inserted in frame with the target gene and the reading frame is maintained, a functional fusion gene may arise, which then may be phenotypically relevant [Newman et al., 2015]. This can only be decided upon after the nucleotide sequences of the breakpoints at the site of insertion have been determined [Newman et al., 2015]. Since most ITs may be phenotypically neutral, they will remain undetected if only copy number profiling of patients, and not of healthy relatives, is performed.

In a recent study, the nucleotide sequences of the breakpoints have been determined in both the patient and in the parents from whom the ITs were inherited [Kurtas et al., 2019]. In 3 families, a duplication on an otherwise unaffected chromosome as a by-product of chromothripsis was found. In 1 case, a chromosome 3 underwent chromothripsis and, subsequently, a crossingover with the normal chromosome 3 occurred. As a re- sult, the mother retained a diploid karyotype but carried 2 rearranged chromosomes 3 . On one of them, an inversion had taken place, and 1 segment of chromosome $3 \mathrm{q}$ appeared inserted into chromosome 8 . The sequences surrounding the breakpoint junctions indicated that they were fused by nonhomologous end joining (NHEJ). In a second case, chromosomes 6 and 14 of the father had undergone a chromothriptic rearrangement and 1 fragment of chromosome 14 was retrieved on chromosome 22p. In the third case, a $t(6 ; 7 ; 15)$ in the healthy mother most likely resulted from a 3-way chromoplexy-chromothripsis event akin to a case reported earlier [Kloosterman et al., 2011]. This rearrangement probably had taken place in the germline of the grandmother of the index patient. Although a few breakpoints were flanked by Alu-sequences, those at the majority of fragment fusion points in all 3 cases were consistent with NHEJ. This contradicts Alumediated chromothripsis as the underlying mechanism [Nazaryan-Petersen et al., 2018]. Chromothripsis after telomere crisis and breakage-fusion-bridge cycles affects a single arm of the involved chromosome [Maciejowski et al., 2015]. Since in the first case, both arms of chromosome 3 were affected, this also seems improbable as the underlying mechanism.

An alternative mechanism may be lagging of 1 or several chromosomes during anaphase, which then become integrated into a micronucleus. There, the chromosomes may undergo a process of shattering and re-assembly of segments, during which some may be lost while others are integrated in another chromosome [Crasta et al., 2012; Zhang et al., 2013, 2015]. This re-assembly may involve both canonical and alternative NHEJ [Slamova et al., 2018; Poot, 2018]. As yet, it is not clear what may trigger the shattering process and what may be the underlying biochemical mechanism(s). Interestingly, lymphoblastoid cell cultures defective for the WRN encoded $3^{\prime}->5^{\prime}$ helicase $-3^{\prime}->5^{\prime}$ exonuclease protein are hypersensitive to double-strand breaks- and interstrand cross-links-inducing drugs, which is reflected in higher levels of micronuclei [Ogburn et al., 1997; Poot et al., 1999, 2001, 2002, 2004; Honma et al., 2002]. Of note is that the membranes of micronuclei lack several proteins that are core components of the nuclear envelope. For instance, in micronuclei the amount of lamin B1 is strongly diminished, nuclear pore complex proteins are not detectable, and they lack proteasomes [Hatch et al., 2013; Liu et al., 2018; Maass et al., 2018]. In larger micronuclei, some lamin B1 is present, however [Kneissig et al., 2019]. On the other hand, micronuclei retain the BLM-encoded $3^{\prime}->5^{\prime}$ exonuclease and show significant increases in emerin [Yanki- 
wski et al., 2000; Maass et al., 2018]. Missegregated chromosomes in experimentally generated micronuclei exhibit a 120-fold higher susceptibility to developing chromosomal aberrations, in particular translocations, insertions, deletions, and complex rearrangements [Ly et al., 2019]. These appeared to be the result of chromothripsis followed by canonical NHEJ.

Regardless of its underlying mechanism(s), which will need more research, a few clinical ramifications have become evident. In cases in which 1 or several seemingly de novo duplications are detected, FISH for the duplicated fragments in both the patient and the parents is necessary. The latter test has to establish whether the duplicated segment is located in cis, most likely in tandem, which will appear as a single FISH signal. If the FISH signal can also be seen at a remote site, this may be due to an intrachro- mosomal duplication process. If the FISH signal appears on another chromosome, it reflects an IT. In such cases, the duplication has not arisen de novo but has been transmitted by an unaffected, diploid carrier parent. The recurrence risk for such an event is 1 in 4 , which is considerably higher than that for a "mere" duplication. Since such ITs may occur in healthy individuals as a result of a "balanced" chromothripsis event, they represent a underrecognized "genomic gremlin" in need of more attention [Kurtas et al., 2019].

Martin Poot

\section{Conflict of Interest Statement}

The author declares no conflict of interest.

\section{References}

Beck CR, Carvalho CM, Banser L, Gambin T, Stubbolo D, Yuan B, et al. Complex genomic rearrangements at the PLP1 locus include triplication and quadruplication. PLoS Genet. 2015 Mar;11(3):e1005050.

Bertelsen B, Nazaryan-Petersen L, Sun W, Mehrjouy MM, Xie G, Chen W, et al. A germline chromothripsis event stably segregating in 11 individuals through three generations. Genet Med. 2016 May;18(5):494-500.

Carvalho CM, Lupski JR. Mechanisms underlying structural variant formation in genomic disorders. Nat Rev Genet. 2016 Apr;17(4):22438.

Crasta K, Ganem NJ, Dagher R, Lantermann AB, Ivanova EV, Pan Y, et al. DNA breaks and chromosome pulverization from errors in $\mathrm{mi}$ tosis. Nature. 2012 Jan;482(7383):53-8.

Gu S, Szafranski P, Akdemir ZC, Yuan B, Cooper ML, Magriñá MA, et al. Mechanisms for Complex Chromosomal Insertions. PLoS Genet. 2016 Nov; 12(11):e1006446.

Hannes FD, Sharp AJ, Mefford HC, de Ravel T, Ruivenkamp CA, Breuning MH, et al. Recurrent reciprocal deletions and duplications of 16p13.11: the deletion is a risk factor for MR/ MCA while the duplication may be a rare benign variant. J Med Genet. 2009 Apr;46(4): 223-32.

Hatch EM, Fischer AH, Deerinck TJ, Hetzer MW. Catastrophic nuclear envelope collapse in cancer cell micronuclei. Cell. 2013 Jul;154(1): 47-60.

Honma M, Tadokoro S, Sakamoto H, Tanabe H, Sugimoto M, Furuichi Y, et al. Chromosomal instability in B-lymphoblasotoid cell lines from Werner and Bloom syndrome patients. Mutat Res. 2002 Sep;520(1-2):15-24.
Kloosterman WP, Guryev V, van Roosmalen M, Duran KJ, de Bruijn E, Bakker SC, et al. Chromothripsis as a mechanism driving complex de novo structural rearrangements in the germline. Hum Mol Genet. 2011 May;20(10): 1916-24.

Kloosterman WP, Tavakoli-Yaraki M, van Roosmalen MJ, van Binsbergen E, Renkens I, Duran $\mathrm{K}$, et al. Constitutional chromothripsis rearrangements involve clustered doublestranded DNA breaks and nonhomologous repair mechanisms. Cell Rep. 2012 Jun;1(6): 648-55.

Kneissig M, Keuper K, de Pagter MS, van Roosmalen MJ, Martin J, Otto H, et al. Micronuclei-based model system reveals functional consequences of chromothripsis in human cells. eLife. 2019 Nov;8:e50292.

Kurtas NE, Xumerle L, Giussani U, Pansa A, Cardarelli L, Bertini V, et al. Insertional translocation involving an additional nonchromothriptic chromosome in constitutional chromothripsis: rule or exception? Mol Genet Genomic Med. 2019 Feb;7(2):e00496.

Liu P, Erez A, Nagamani SC, Dhar SU, Kołodziejska KE, Dharmadhikari AV, et al. Chromosome catastrophes involve replication mechanisms generating complex genomic rearrangements. Cell. 2011 Sep;146(6): 889-903.

Liu S, Kwon M, Mannino M, Yang N, Renda F, Khodjakov A, et al. Nuclear envelope assembly defects link mitotic errors to chromothripsis. Nature. 2018 Sep;561(7724):551-5.

Lupiáñez DG, Spielmann M, Mundlos S. Breaking TADs: How Alterations of Chromatin Domains Result in Disease. Trends Genet. 2016 Apr;32(4):225-37.
Ly P, Brunner SF, Shoshani O, Kim DH, Lan W, Pyntikova T, et al. Chromosome segregation errors generate a diverse spectrum of simple and complex genomic rearrangements. Nat Genet. 2019 Apr;51(4):705-15.

Maass KK, Rosing F, Ronchi P, Willmund KV, Devens F, Hergt M, et al. Altered nuclear envelope structure and proteasome function of micronuclei. Exp Cell Res. 2018 Oct;371(2): 353-63.

Maciejowski J, Li Y, Bosco N, Campbell PJ, de Lange T. Chromothripsis and Kataegis Induced by Telomere Crisis. Cell. 2015 Dec: 163(7):1641-54.

Madan K. What is a complex chromosome rearrangement? Am J Med Genet A. 2013 May; $161 \mathrm{~A}(5): 1181-4$

Nazaryan-Petersen L, Eisfeldt J, Pettersson M, Lundin J, Nilsson D, Wincent J, et al. Replicative and non-replicative mechanisms in the formation of clustered CNVs are indicated by whole genome characterization. PLoS Genet. 2018 Nov; 14(11):e1007780.

Newman S, Hermetz KE, Weckselblatt B, Rudd MK. Next-generation sequencing of duplication CNVs reveals that most are tandem and some create fusion genes at breakpoints. Am J Hum Genet. 2015 Feb;96(2):208-20.

Nowakowska BA, de Leeuw N, Ruivenkamp CAL, Sikkema-Raddatz B, Crolla JA, Thoelen R, et al. Parental insertional balanced translocations are an important cause of apparently de novo CNVs in patients with developmental anomalies. Eur J Hum Genet. 2012 Feb;20(2):166-70.

Ogburn CE, Oshima J, Poot M, Chen R, Hunt KE, Gollahon KA, et al. An apoptosis-inducing genotoxin differentiates heterozygotic carriers for Werner helicase mutations from wildtype and homozygous mutants. Hum Genet. 1997 Dec;101(2):121-5. 
de Pagter MS, van Roosmalen MJ, Baas AF, Renkens I, Duran KJ, van Binsbergen E, et al. Chromothripsis in healthy individuals affects multiple protein-coding genes and can result in severe congenital abnormalities in offspring. Am J Hum Genet. 2015 Apr;96(4): 651-6.

Poot M, Gollahon KA, Emond MJ, Silber JR, Rabinovitch PS. Werner syndrome diploid fibroblasts are sensitive to 4-nitroquinoline- $\mathrm{N}$ oxide and 8-methoxypsoralen: implications for the disease phenotype. FASEB J. 2002 May;16(7):757-8.

Poot M, Gollahon KA, Rabinovitch PS. Werner syndrome lymphoblastoid cells are sensitive to camptothecin-induced apoptosis in Sphase. Hum Genet. 1999 Jan;104(1):10-4.
Poot M, Haaf T. Mechanisms of Origin, Phenotypic Effects and Diagnostic Implications of Complex Chromosome Rearrangements. Mol Syndromol. 2015 Sep;6(3):110-34.

Poot M, Jin X, Hill JP, Gollahon KA, Rabinovitch PS. Distinct functions for WRN and TP53 in a shared pathway of cellular response to $1-\beta$-D-arabinofuranosylcytosine and bleomycin. Exp Cell Res. 2004 Jun;296(2):327-36.

Poot M, Yom JS, Whang SH, Kato JT, Gollahon KA, Rabinovitch PS. Werner syndrome cells are sensitive to DNA cross-linking drugs. FASEB J. 2001 May;15(7):1224-6.

Poot M. Genes, Proteins, and Biological Pathways Preventing Chromothripsis. Methods Mol Biol. 2018;1769:231-51.

Slamova Z, Nazaryan-Petersen L, Mehrjouy MM, Drabova J, Hancarova M, Marikova T, et al. Very short DNA segments can be detected and handled by the repair machinery during germline chromothriptic chromosome reassembly. Hum Mutat. 2018 May;39(5):709-16.
Yankiwski V, Marciniak RA, Guarente L, Neff NF. Nuclear structure in normal and Bloom syndrome cells. Proc Natl Acad Sci USA. 2000 May;97(10):5214-9.

Zhang CZ, Leibowitz ML, Pellman D. Chromothripsis and beyond: rapid genome evolution from complex chromosomal rearrangements. Genes Dev. 2013 Dec;27(23):2513-30.

Zhang CZ, Spektor A, Cornils H, Francis JM, Jackson EK, Liu S, et al. Chromothripsis from DNA damage in micronuclei. Nature. 2015 Jun;522(7555):179-84.

Zhang L, Wang J, Zhang C, Li D, Carvalho CM, Ji $\mathrm{H}$, et al. Efficient $\mathrm{CNV}$ breakpoint analysis reveals unexpected structural complexity and correlation of dosage-sensitive genes with clinical severity in genomic disorders. Hum Mol Genet. 2017 May;26(10):1927-41. 